\title{
Company activities for managing customer equity
}

Received (in revised form): 21st April, 2004

\section{Behram Hansotia}

is Co-founder, President and Chief Executive Officer of InfoWorks. His expertise lies in designing information-intensive marketing processes for customer acquisition, development and win-back. The approach is embodied in InfoWorks' Customer Value Enhancement ${ }^{\mathrm{TM}}$ process. Behram's post-doctoral experience spans academia, industry and management consulting, with the past several years devoted exclusively to strategic database marketing. Behram has been an adjunct professor in the graduate Integrated Marketing Communications programme at Northwestern University, has served as a member of the Editorial Board of the Journal of Interactive Marketing and currently serves on the International Editorial Board of this journal.

\begin{abstract}
The last decade has seen significant interest in a new model of enhancing the performance and competitiveness of businesses by directly managing the firm's customer equity, or the lifetime value of the firm's customer franchise. In this model, customers are viewed as assets and the firm's key function is to develop and build its total customer equity. This paper discusses how firms should organise their processes and activities to successfully manage and build equity in their customer base.
\end{abstract}

\section{INTRODUCTION}

Over the last few years, many companies have made significant investments in customer relationship management (CRM) software based on a leap of faith that enhanced software-assisted interactions with customers would lead to more satisfied customers, who in turn would give the company a larger share of their business and maintain their relationship with the company longer. This has not always turned out to be the case. As a result, companies have blamed the software vendors and have accused them of claiming greater benefits than their products deliver. The vendors in turn have responded that the companies did not have the right processes and, as a result, were not able to derive maximum benefit from these systems. Though some companies have abandoned their CRM initiatives, many are taking a fresh look at how they can improve both the planning and implementation of CRM.

Many companies looked at CRM as a systems initiative to help reduce costs through improved efficiencies in managing customer interactions and did not give enough consideration to the ultimate objective, namely enhancement of customer equity or the long-term value of their customer franchise. The CRM systems they had purchased were what may specifically be described as CRM execution systems. Most were designed to help service representatives interact meaningfully with customers, using recent and historic customer interaction and transaction data. Since there was no direct focus on enhancing customer equity, however, typically no significant incremental improvement in customer performance or return on investment (ROI) was observed.

Hansotia ${ }^{1}$ discussed the prerequisites for the successful implementation of CRM and Kim, Suh and Hwang ${ }^{2}$ have presented a model for evaluating the effectiveness of CRM.

Continually enhancing customer equity is a singularly challenging task and needs dedicated focus to achieve. It 
requires leveraging technology but, more importantly, it requires companies to recognise that this is potentially the single biggest change in their strategy. Since strategy is all about being different, and at its heart is making decisions about what activities a firm should focus on and develop outstanding capabilities in, when a firm sets about making continuous enhancements in customer equity as its major goal, it implies a major refocusing of and changes in its:

- Marketing activities and effort;

- Metrics used to manage marketing effort and allocate marketing resources; and

- Marketing organisational structure and core competencies.

This paper first discusses the concept of customer equity and why it is important for companies to learn how to manage and enhance it. It next discusses specific industries where it is much easier to implement this strategy and then presents a customer lifecycle approach to managing customers and customer equity.

\section{CUSTOMER EQUITY: WHAT IT IS AND WHY SHOULD COMPANIES LEARN TO MANAGE IT}

Financial theory tells us that the net present value (NPV) of its projected cash flow may estimate the value of a company (Van Horne ${ }^{3}$ ). Investment companies use this model extensively to determine if there are potential opportunities in the market place.

According to this model, if the imputed price of a share (based on the analyst's cash flow projections) is higher than its current price, then it implies that the stock is either not correctly valued or the analyst's cash flow predictions are too optimistic. Analysts do not have all the information on a firm to develop these cash flow projections and therefore rely on the company's historical financial results, information provided to them by management (company strategy) and their own understanding and knowledge about the industries in which the company operates. CEOs understand this and devote considerable time to 'talking up' their companies and explaining their overall strategy to analysts and the financial media.

This financial model views a company as a collection of assets that throw off cash flow and recognises that management's most critical job is to develop and execute strategies to manage these assets so as to continuously grow cash flows. The concept of customer equity views customers as a company's most important asset, since ultimately cash flows are based on customer-generated revenues and the investments made to generate those revenues. Managing customer equity therefore means determining which customer investments a company should make and how it should make them. It also means determining the activities a company should engage in to increase customer cash flows and how it should evaluate which marketing efforts are worth investing in. To continuously grow total company cash flows, a company must, therefore, continuously increase customer-generated cash flows. This can be done by increasing the number of active customers and/or increasing the equity (lifetime value) of at least some of the customers. This means:

- Acquiring only those customers whose lifetime value exceeds the marketing cost of acquiring the customer, thereby creating surplus value.

- Continuously developing customers through add-on selling and making marketing investments so that the 
increase in customer equity (NPV of incremental cash flows) exceeds the cost of the add-on selling.

- Retaining profitable customers for as long as possible and making customer retention investments such that the resulting increase in customer equity exceeds the (present value of the) cost of the retention programme.

Note these activities are not independent. As a company increases the average lifetime value of its customers, either through add-on selling or retention, it can afford to spend more on acquiring customers, and, if this money is spent wisely, it should be able to increase the number of new customers it would acquire thereby enhancing the total equity of its customer base. Like everything else, however, there are diminishing returns. As a company succeeds in increasing customer equity, it gets more and more difficult to find investment opportunities to further increase customer equity. This implies that there are optimal spend levels for acquisition, add-on selling and retention (See Blattberg et al. ${ }^{4}$ and Blattberg and Deighton $^{5}$ for an excellent discussion on this topic).

How high a company can increase its customer equity depends on how well it understands its customers, how competitive its products and services are, how well it makes its pricing decisions, how well it targets its marketing investments and where the company stands in its development cycle, since mature companies have to innovate furiously to continue to grow their total customer equity. What is clear, however, is that the value of a company is essentially the aggregate of the value of its current and future customers. Gupta et al. ${ }^{6}$ provide examples of how, even with relatively simplified assumptions and publicly available data, this approach to assessing company value comes remarkably close to certain companies' market capitalisation. This implies that increasing customer equity leads to increases in both share price and market capitalisation.

\section{STATE OF AFFAIRS IN INDUSTRIES MOST SUITED TO MANAGING CUSTOMER EQUITY}

The model described above implies that management can make rational marketing investment decisions based on customer data. End-customer transaction data are more readily available in industries such as banking, insurance, airlines, hospitality and, more and more, retailing, due to the integration of point-of-sale systems using customer loyalty and house and bank credit cards with customer databases. Even though companies in these industries routinely collect customer transaction and company-customer interaction data, very few single-mindedly deploy this customer level investment model of marketing. Bell et al. ${ }^{7}$ present seven barriers to customer equity management in their paper. The present author discusses four specific issues in this paper that prevent a company from organising itself and managing to maximise customer equity:

- Technology and systems infrastructure.

- Fear and concerns about change.

- Organisational alignment.

- Knowledge and skill base to execute this model of marketing.

In the 1990s, technology and systems infrastructure investments - in terms of creating an integrated view of the customer - has been widely addressed by many companies in these industries. Today, many customer databases routinely track all transaction data, such as purchases, payments, returns etc. Less 
readily available are data on customer-company interactions as they occur across all channels. Many of the CRM systems mentioned earlier are designed to capture and track this information. For such tracking to be successfully carried out, however, often requires training and new processes. Sales people typically are very possessive of their customer relationships and often vigorously resist any change, particularly if it requires additional activities such as making computer entries that capture details about their selling efforts.

Many companies in the information-intensive industries, who have invested in the right information architecture, have used customer information mostly tactically to carry out only direct marketing programmes. Though such efforts may contribute to increasing customer equity, very few companies track the right metrics to ensure that these investments are consistently enhancing the value of the customer franchise. This is because even though the information exists to implement the customer equity management approach to marketing, many of these companies still operate under a package goods marketing paradigm of brand building through large general media advertising budgets. This is akin to refusing to turn on the light in a dark room even when your home has electricity. The reasons for this are many, and include inertia, lack of a clear mandate and fear of change.

Companies are also not organised in a fashion that enables them to focus on monitoring customer equity and analysing the impact of acquisition, add-on selling and retention programmes on customer equity. Companies are typically organised around products, geography or customer types, or some combination of these three factors.

Retailers, for instance, are often organised into divisions around merchandise groupings and each division often has its own separate marketing budget. The retailers' focus is on division level sales, and marketing resources are often allocated based on these sales. The company may have a central direct marketing group to execute programmes as requested by the divisions, but most of the company's advertising budget goes towards general media advertising and newspaper inserts. Hence almost nobody focuses on understanding the dynamics of the business from the customer's perspective.

Banks are often organised around customer types; for example, commercial customers, small businesses, consumers and high-end consumers for private banking services. Nonetheless, even when companies are organised around customers, they generally take either a product perspective or an operational perspective in serving customers, and do not focus explicitly on managing customer equity. A few leading banks, however, have done significant work in understanding customer equity and target their marketing efforts on the basis of generating positive incremental ROIs.

Companies who have their roots in direct marketing are typically leaders in targeting prospects and in add-on selling. Very few, however, drive all marketing investment decisions based explicitly on enhancing customer equity.

\section{ACTIVITIES FOR ENHANCING CUSTOMER EQUITY}

A company's total customer equity may be written as the product of the number of customers multiplied by the average lifetime value of its customers:

Total customer equity $=($ Number of customers $) \times($ Average customer lifetime value) 
Hence, increasing either or both of the terms on the right hand side can increase total customer equity. Managing customer equity therefore requires the company to focus on activities that maximise this product. This includes developing a knowledge infrastructure that facilitates monitoring of the components of customer equity as well as making resource allocation decisions that increase the value of the above product.

If customer equity (lifetime value) is decomposed into its components namely the initial or new customer equity and the veteran customer equity resulting from future purchases - the activities needed to increase the value of this product can be identified.

Customer equity $=($ New customer equity $)+($ Veteran customer equity)

Where

New customer equity $=($ Cash flow from initial purchase) - (Marketing and servicing costs prior to the second purchase) $=($ Revenues from initial purchase $)-$ (Cost of goods sold) - (Cost of processing and fulfilling the initial order) - (Marketing acquisition cost of the new customer) - (Marketing and customer servicing costs prior to the second purchase)

The marketing acquisition cost may or may not be included in the above identity, depending on the application. Later, in order to determine how much a company should spend on acquiring a new customer, this initial cost is considered separately, since it is this investment that creates the future customer-generated cash flows.

The author refers to the time horizon over which the new customer equity is computed as the new customer spell. Each company, depending on its business, needs to develop its own definition for its new customer spell. In the above example, it was defined as the time until the second purchase after which, the customer is designated as a veteran customer. Later on in this paper alternate approaches, based on hazard models are discussed. Also, for the sake of simplicity, the marketing and servicing costs were not discounted after the first purchases but prior to the second purchase. If the time between purchases is large, these costs should also be discounted to their present value.

The veteran customer equity is given by:

Veteran customer equity $=$ Present value of cash flows from future purchases, starting with the second purchase

Though the above identities appear to be referring to tangible products, after some adjustments they are equally valid for services as well. As an example, consider the telecommunications industry. Many 'phone companies today sell combined local and long distance calling packages for a fixed monthly fee of around $\$ 45$. For this price they allow customers to use the 'phone as much as they like. Since this is a contractual product, purchases ('phone usage), though discrete, can be viewed as continuous.

The cash flow associated with the initial purchase (new customer equity) may be defined as the cash flow for the first period. The duration of this first period will depend on the billing cycle the customer is assigned to. If, for instance, the customer is assigned to the tenth billing cycle in the month, ending on the 20th of each month, and the customer's start date is, say, 11th June, 
then this customer's first period will be ten days in duration. Typically, the billing for this first period will be prorated to account for this shorter initial period. The variable costs for this first period typically will include:

- The marketing cost of creating the new customer;

- The cost of accepting the order and opening the account;

- The cost of sending out a 'welcome new customer' package;

- The cost of billing for the first period;

- The access costs the company has to pay other carriers for the 'phone calls routed over their networks;

- The expected customer service costs incurred when (a small percentage of?) new customers call in with questions about their service;

- The expected cost of bad debt (there would typically be a very small percentage of customers who may not pay their first bill); and

- The expected loss of revenue if a customer cancels the service in the first period and the associated cost of terminating the account (this would depend on the terms of the contract).

Although this is just an example, it illustrates how the nuances of each industry can potentially impact the cash flow calculations. Note that many of the costs depend on customer behaviours, extent of calling, long-distance versus local calls, calls for customer service etc. Also, in the above example only variable costs that are specifically associated with customer behaviours and did not include such fixed costs as network and other fixed asset depreciation, network maintenance, management compensation etc were included. None of these costs change in the short run as the number of customers changes. Whether such costs should be included or not is not always clear. The authors' recommendation is to make that decision based on how the customer equity calculation is to be used. If, for instance, the application is to determine whether a specific prospect or prospect segment should be contacted, then it makes sense not to include such fixed costs, since here one would like to invest in all prospects whose expected long term (discounted) contribution to overhead and profits is positive. On the other hand, if one were building a financial model of the company based on customer inflows and outflows over several years, then one would need to account for the capital investments to be made based on the size of the customer base.

The veteran customer equity depends significantly on future customer behaviours. As well as some of the above costs, revenues may also increase in the future, based on the likelihood of customers signing on for additional services such as broadband internet services, additional phone lines and vertical services such as conference calling, call waiting, number identification etc. The future cash flows may also terminate in any month if the customer decides to cancel the service for any reason. The cash flows should thus include the marketing costs of selling add-on services as well as the costs of customer retention and 'save' programmes for increasing the duration of the customer relationship.

The details of how customer equity can be computed will not be discussed here, (see instead Berger and Nasr, ${ }^{8}$ Mulhern, ${ }^{9}$ Reinartz and Kumar $^{10}$ and Jain and Singh ${ }^{11}$ for discussions on computations and implications for marketing). As this example illustrates, however, it is not a trivial problem, since 
it involves predicting customer

behaviours. The author's

recommendation would be to first

estimate an average customer's equity and

then determine which cost and revenue

components have high variances. The

next step would be to group customers

so as to explain these variances and then

redo the customer equity calculations by

customer segment. The most

sophisticated approach would be to build

statistical models to predict future

customer behaviours, such as the

likelihood of buying add-on products

and the likelihood of attrition in each

future period. These are typically hazard

or survival analysis models concerned

with the timing of events. The

modelling is further complicated in this

case, since buying additional products

and attrition are not independent events:

as the likelihood of attrition increases, the likelihood of buying additional products decreases. To build unbiased models, such correlations must be explicitly modelled through a system of equations.

Tangible products have their own complexities. Here, the likelihood of additional purchases and the time between purchases are critical. Also, the magnitude of each purchase and its associated profit margin will depend on the mix of products purchased.

Needless to say, considerable additional work needs to be done before customer equity calculations can be standardised for different industries. It is important, however, to start with simple models and then to improve the precision of the estimates over time, as the company builds greater expertise. Significant benefits can accrue even with relatively simple models. In fact, like anything else, beyond a certain point there will probably be diminishing returns as additional complexities are introduced into the analysis.
The above identities also directly lend themselves to identifying the activities a company should engage in to continually increase its total customer equity. These include:

- Customer acquisition;

- Customer development (add-on selling); and

- Customer retention.

Each of these activities it discussed next, as well as how decisions in any one of these areas impact the other areas.

\section{CUSTOMER ACQUISITION}

The decisions made in acquiring new customers impact both new and veteran customer equity. Key questions a company needs to answer include:

- How much should the company spend on acquiring different customer types?

- What product should the company lead with, and at what price?

- What should be the overall value proposition and how should it be presented?

- What media should the company deploy, and how should it allocate funds across different media?

The first question is intimately related to customer equity. A company should spend more on prospects who will have higher customer equity than those who will have lower customer equity. The way the author approaches the first question is to redefine customer equity as the present value of customer-generated cash flows after a potential customer has signed on. Applying this definition to the right hand side of the identity and using the standard decision rule of capital budgeting: 'Accept all projects that have NPVs greater than or equal to zero', gives us: 
(Customer equity) - (Marketing acquisition cost of new customer) $\geq 0$ or

(Marketing acquisition cost of a new customer $\leq$ (Customer equity)

Note that when the marketing acquisition cost equals the customer equity, the internal rate of return on the marketing acquisition investment equals the discount rate used in the NPV calculation. If this discount rate is the firm's cost of capital, then the above rule will generate internal rates of return on the marketing investment at least equal to the firm's cost of capital. If prospects are rank ordered on net customer equity (NCE) - (after acquisition costs) - and all prospects with expected NCEs greater than or equal to zero are selected, then this rule will ensure that the total customer equity generated from the acquisition campaign will be maximised. This is similar to the decision rule of making only those investments that result in a positive economic value add (EVA). Since different customers have different customer equity values, to apply this rule, one needs to be able to estimate the acquisition costs of different prospects and their resulting customer equities, if they do become customers.

The author next discusses how this rule can be applied; it is discussed in the context of database and direct marketing, since this allows for targeting individual prospects based on their profiles. Other direct response media, such as print advertisements, direct response television (DRTV) advertising etc can also apply this rule, but only at the campaign level. For instance if the value of the average customer equity generated from DRTV advertising on particular shows is known, this rule requires us to limit the marketing acquisition cost per customer to the average customer equity value.
Many companies use direct marketing, either in conjunction with other media to acquire new customers or by itself. Companies who sell to businesses often use different marketing channels based on customer size and potential. A dedicated sales force generally targets large businesses whereas small to intermediate size companies are targeted using direct marketing. Luxury automobile manufacturers, knowing they have a finite market for their products, also use direct marketing (in conjunction with brand advertising through print, television and other media) extensively, as do credit card companies.

Some of the more sophisticated direct marketers have developed proprietary prospect databases that not only maintain basic demographic information on their prospects but the company's contact history as well. In such cases, a company can not only test different acquisition campaigns but can get a reasonably accurate understanding about its customer acquisition costs and the longitudinal effects of contacts on prospects' response behaviour. Since such companies typically also track all future purchases and marketing expenditures on their customer base, they can also estimate their prospects' customer equity if they become customers. (The initial customer acquisition cost is not included here, since the objective is to estimate it for each prospect.) The next step would be to estimate each prospect's expected customer equity if he/she became a customer. There are many ways to do that. One way would be to first segment the existing customer base on customer equity and then, using only information available on prospects, build a model that predicts the probabilities of a prospect becoming a member of each of those segments if he/she became a customer. This can be done with a polychotomous logistic regression model. 
Once each prospect's segment membership probabilities and the segments' mean customer equities are estimated, each prospect's expected customer equity can be calculated by the (probability) weighted average of the segments' mean customer equity values. This expected customer equity should be the upper bound of the customer acquisition cost. The customer acquisition cost is the ratio of the marketing cost of contacting each prospect divided by the likelihood of converting the prospect into a customer as a result of the contact(s). This conversion likelihood for each prospect can be estimated with a logistic regression model developed using the information on the prospect database. Prospects can now be sorted on their net expected customer equity (expected customer equity minus acquisition cost) and all prospects with values greater than or equal to zero selected for the campaign.

The remaining three questions posed under customer acquisition are all related to the details of the acquisition campaigns, namely the lead product that should be offered, its price, its positioning (benefits and value proposition) and the media that should be deployed in targeting new customers. The answers to these questions cannot be obtained easily or quickly, since they can only be derived through systematic tests in the marketplace. The science of design of experiments (Box and Draper ${ }^{12}$ ) see also Hansotia ${ }^{13-15}$ for direct marketing applications) becomes an invaluable tool in accomplishing this. The best way to again evaluate competing offers, however, is through customer equity. Though the ultimate approach may involve making these decisions at the prospect level, so that for each specific prospect profile the offer and the spend levels that maximise net customer equity are identified, initially one may want to make these decisions at the prospect segment level. This is, however, a little like the chicken and egg. Since the elements of the offer and its marketing execution will drive not only the acquisition cost (conversion rate and cost of contact) but also the initial cash flow from the new customer, as well as the present value of cash flows from future purchases. The challenge, therefore, is to be able to take the early findings from a test and extrapolate those results over the longer time period that is required to estimate the veteran customer's equity. Typically, however, if one can reduce the acquisition cost without impacting the rest of the cash flows associated with customer equity, it will be possible to contact more prospects and generate more new customers, thus increasing the total net customer equity created through the new customer campaign.

\section{CUSTOMER DEVELOPMENT THROUGH ADD-ON SELLING}

Once a customer is acquired, the marketing challenge is to be even more efficient than in the past at selling additional products and services. This is the only way customer equity can be further enhanced through add-on selling. Since the customer was acquired based on limiting the acquisition cost to at most the value of the customer's equity, which already accounts for cash flows from future purchases, selling add-on products at the same efficiency rate as in the past will not enhance the value of the customer base. Essentially the company needs to either improve its targeting capabilities by better matching specific offers to different customer types, or offer brand new products that entice customers to give the company more business than they would do otherwise. For companies selling tangible products, 
developing customers through add-on selling is equivalent to increasing the average order size as well as potentially the average purchase rate.

A great example of add-on selling is that provided by UPS Supply Chain Solutions (SCS), a $\$ 2.5$ bn subsidiary of UPS. SCS is big in the equipment repair business. It has extended its service line not only picking up equipment that needs repairing, but by doing the repair for their client manufacturers and returning the refurbished product back to the customer in record time. The manufacturers train UPS engineers and, most of the time, the end customer is not even aware that the repair work is being done by UPS.

Developing customers, therefore, essentially involves either increasing the customer's share of wallet so the company gets all the customer's business for the product categories it sells or introducing the customer to new product categories. Doing this well requires a deep understanding of customer needs and a singular focus on ensuring flawless customer experiences. Beyond that, it requires extensive testing and development of targeting tools that can help answer which customers should be presented with what products, when, at what price and how the offer should be presented. Again, the decision making should be based on generating positive incremental cash flow compared to previous marketing programmes. This can be identified through testing, by comparing cash flow per customer under the enhanced approach to the cash flow under the previous approach.

After establishing that the new approach outperforms the previous one, results can be extrapolated to the future and the veteran customer equity can be recalibrated upwards. It is important to continue to track the cash flows for some time into the future to ensure that the observed lift in cash flows tracks the projections made earlier. The updated customer equity values may now be used to target new customers even more aggressively.

\section{CUSTOMER RETENTION}

While add-on selling focuses on enhancing the magnitude of cash flows generated from additional purchases, customer retention focuses on enhancing the duration of the cash flows. (See Hansotia $^{16}$ for a discussion on attrition analysis for continuities or contractual services.) For contractual services this is equivalent to maintaining or reducing the customer attrition rate, for tangible products it means maintaining or increasing the purchase rate or the frequency of purchases. In reality, however, customer development and customer retention are intimately linked. Meeting more of a customer's needs through add-on selling increases loyalty and creates disincentives for taking business elsewhere. As long as the company continues to provide value from the customer's perspective, the more products a customer buys from the company, and the longer he or she stays with the company, the greater will be the inertia of the customer staying with the company. Even if another company provides slightly cheaper products, the convenience and perceived risk of moving will typically retain the customer. Obviously if the company's products (and services) are generic and can be easily replicated by others, or if the company is a distributor of branded products and does not offer any unique add-on services, the customer can be enticed away more easily through reduced pricing.

Enhancing customer equity through customer retention requires companies to 


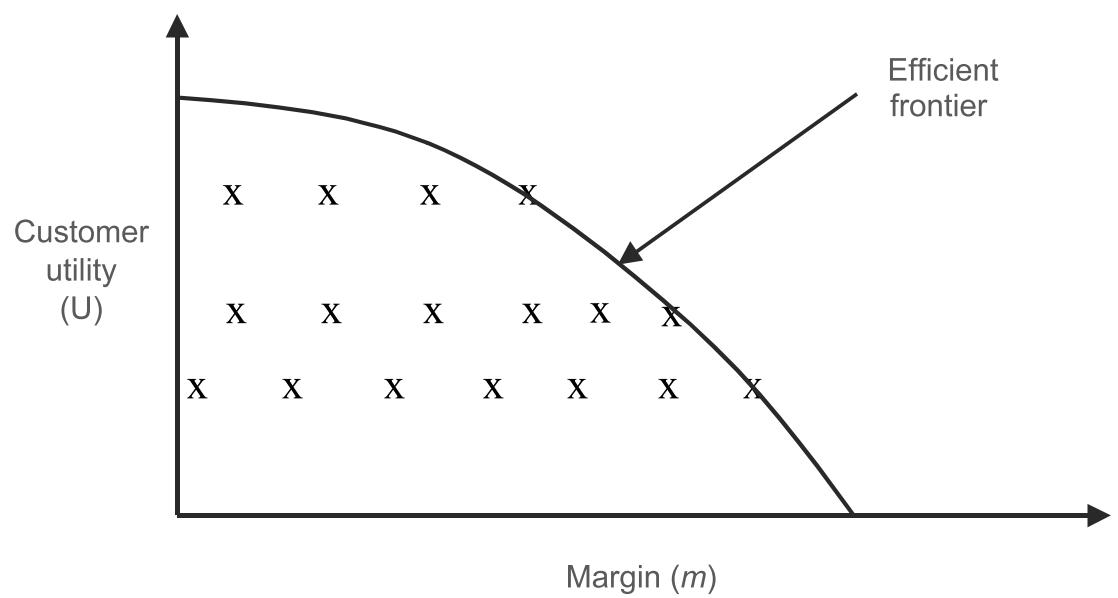

Figure 1: Efficient frontier of customer utility $v$ product margin

group customers by their predicted attrition rates or purchase rates and then target specific programmes that decrease the attrition rate or increase the purchase rate. A programme is successful if it generates incremental cash flow after marketing costs that is positive and sustainable. Again, deep customer knowledge can help companies design meaningful programmes and testing can help identify the successful ones. (See Hansotia and Rukstales for modelling incremental value ${ }^{17}$.)

\section{ROLE OF THE VALUE PROPOSITION AND PRICING}

The value proposition is the bundle of benefits and features provided by a product or service at a given price. The company incurs costs in providing the benefits, which it must more than recover through the price. The difference between the price and the total cost of the product is the contribution to overheads and profits generated by the sale of the product. The company's challenge is to design the value proposition so as to maximise the contribution to customer equity. This requires that the customers' expected utility for the product is high enough that many customers buy the product repeatedly and, at the same time, the profit margin is also high enough to generate excellent total profits. Bell et al. ${ }^{18}$ refer to this as 'partaging surplus' in form of utility for the customer and profit for the company.

Figure 1 shows a plot of different value propositions, where each value proposition is represented by a given customer segment's utility, $\mathrm{U}$, and the company's margin, $m$. (The customers are segmented so they are homogenous with respect to their utility functions.) The scatter diagram helps identify a set of value propositions that, for a given margin, result in the highest utility for that customer segment. This set may be deemed the utility-margin efficient frontier. For a given profit margin, the value proposition on the efficient frontier dominates all others.

Figure 2 displays the lifetime demand curve, $D=f(m)$, where $D$ is the number of units sold per customer or the number of time periods the customer pays for the services for the value on the efficient frontier, for the customer segment from 


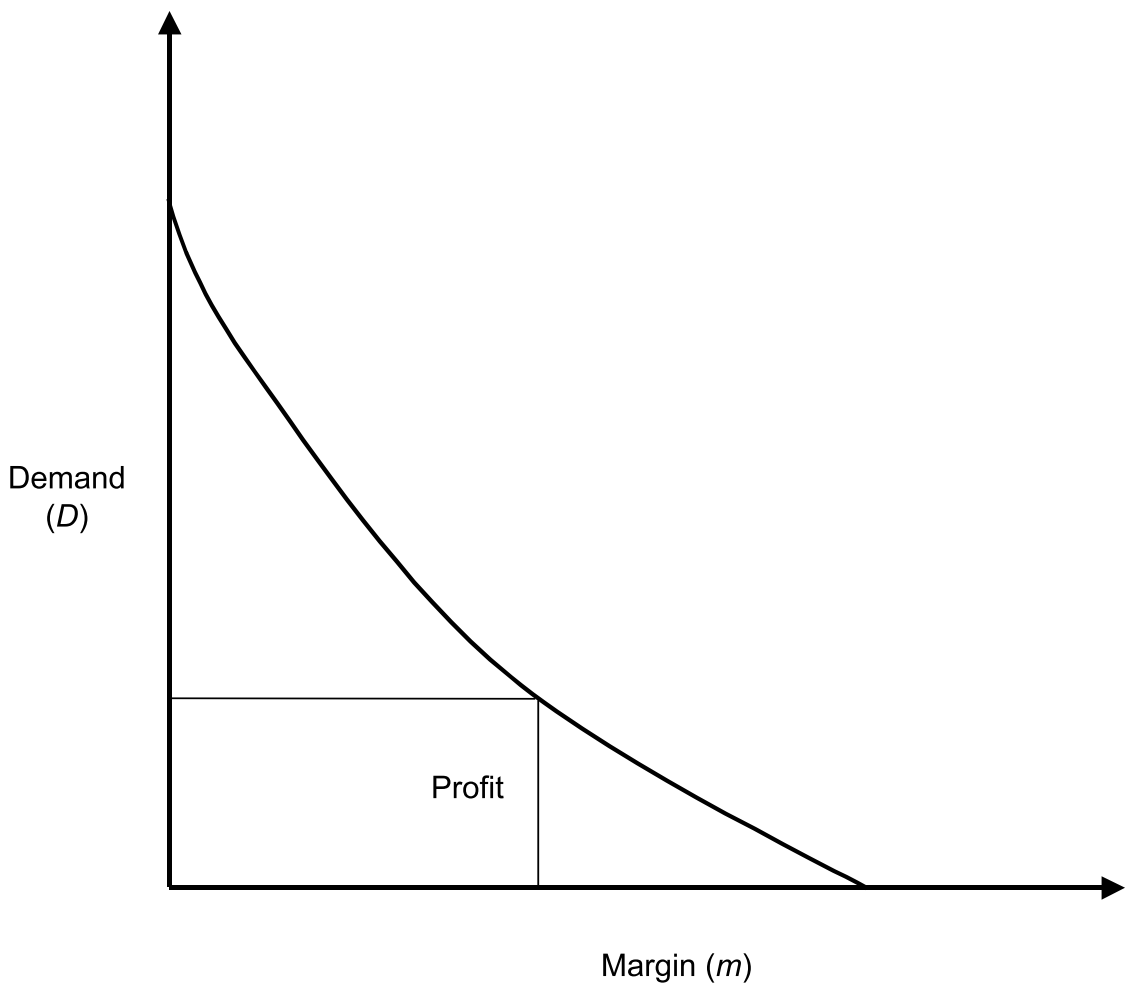

Figure 2: Demand curve for value propositions on efficient frontier

Figure 1. Here, a high margin implies a high price and, consequently, a lower lifetime demand.

For any point on the demand curve, the company's expected lifetime profit per customer, for a given segment, is given by:

$$
P=m f(m)
$$

This is the area of the rectangle of width $m$ and height $D$. The profit margin that maximises $P$ can be obtain by differentiating $P$ with respect to $m$ and then solving for $m$. Hence the margin, $m_{i}^{\star}$ that maximises lifetime profits for segment $i$ is given by the equation:

$$
m_{i}^{\star} f^{\prime}\left(m_{i}^{\star}\right)+f\left(m_{i}^{\star}\right)=0
$$

Here, $f^{\prime}$ is the partial derivative of the function $f(m)$, with respect to $m$.

The utility-based segments can be derived using latent class conjoint analysis. (See DeSarbo, Wedel, Vriens and Ramaswamy ${ }^{19}$ and DeSarbo, Huff, Rolandelli and $\mathrm{Choi}^{20}$ ). Latent class cojoint analysis assumes that customer heterogeneity is captured through a set of segments and derives separate utility functions for each segment. It also derives segment membership probabilities for assigning customers to segments.

The average lifetime demand curve for each segment is more difficult to estimate, since it depends on:

- The likelihood of a customer buying the product/service for the first time;

- The number of times a first time buyer will buy again in the future (tangible products); and

- The number of time periods the customer will pay for the service (contractual products). 
Although difficult to estimate, the demand curve may be estimated through some careful market research. The process of zeroing in on the optimal value proposition and price therefore consists of:

- Estimating the utility function for each segment using latent class conjoint analysis.

- Generating the efficient frontier for each segment.

- Estimating the lifetime demand curve for the products on each efficient frontier.

- Identifying the optimal margin that maximises lifetime profit.

- Identifying the value proposition on the efficient frontier corresponding to the optimal margin.

- Using the cost of the value proposition and its margin to calculate the implied optimal price.

The method described above is conceptual and additional work needs to be done to refine and apply it to real world problems. The approach is also static and over time, as competitors entered the marketplace, the pricing strategy would need to be refined to account for the market dynamics and the lifecycle of the customer. This problem is extremely important and is ripe for further empirical research.

\section{SUMMARY}

The author has discussed the concept of customer equity and how it is related to company value. Today, very few companies methodically pursue activities that maximise the value of their customer franchise. The author suggested that companies focus on four specific activities: customer requisition, customer development, customer retention and designing the right value propositions for its customer segments. He also discussed the key decisions companies need to make in managing these activities, and provided recommendations on how these decisions should be made.

In designing value propositions and pricing them, the author introduced the concept of a utility-margin efficient frontier, since this is the classic game-theoretic trade-off companies engage in with customers. Customers desire to maximise their utility and companies their profits. Then, by introducing a demand curve for the value propositions on the efficient frontier, the author described how the optimal value proposition and its corresponding price could be identified. The suggested approach is conceptual at this point and, though the author has suggested a way to operationalise the solution, this whole problem needs greater empirical attention.

CEOs are under enormous pressure to create shareholder value. The author believes a direct focus on enhancing customer equity is the most direct way to enhance company value. This paper outlined the necessary activities and how they should be carried out. A follow-on article will discuss customer metrics and the organisational design needed to successfully execute these activities.

\section{References}

1 Hansotia, B. (2002) 'Gearing up for CRM: Antecedents to successful implementation', The Journal of Database Marketing and Customer Strategy Management, Vol. 10, No. 2, pp. 121-132.

2 Kim, J., Suh, E. and Hwang, H. (2003) 'A model for evaluating the effectiveness of CRM using the balanced scorecard', Journal of Interactive Marketing, Vol. 17, No. 2, pp. 5-19.

3 van Horne, J. C. (2001) 'Financial Management and Policy', Prentice-Hall, Englewood Cliffs, NJ.

4 Blattberg, R. C., Getz, G. and Thomas, J. S. (2001) 'Customer Equity: Building and Managing Relationships as Valuable Assets', Harvard Business School Press, Boston, MA.

5 Blattberg, R. C. and Deighton, J. (1996) 'Manage 
marketing by the customer equity test', Harvard Business Review, Vol. 74, July-August, pp. 136-144.

6 Gupta, S., Lehmann, D. R. and Stuart, J. A. (2004) 'Valuing customers', Journal of Marketing Research, Vol. XLI, No. 1, pp. 7-18.

7 Bell, D., Deighton, J., Reinartz, W. J. et al. (2002) 'Seven barriers to customer equity management', Journal of Services Research, Vol. 5, No. 1, pp. 77-85.

8 Berger, P. D. and Nasr, N. I. (1998) 'Customer lifetime value: Marketing models and applications', Journal of Interactive Marketing, Vol. 12, Winter, pp. 17-30.

9 Mulhern, F. J. (1999) 'Customer profitability analysis: Measurement, concentration and research directions', Journal of Interactive Marketing, Vol. 13, Winter, pp. 25-40.

10 Reinartz, W. and Kumar, V. (2000) 'On the profitability of long lifetime customers: An empirical investigation and implications for marketing', Journal of Marketing, Vol. 64, October, pp. 17-35.

11 Jain, D. and Singh, S. S. (2002) 'Customer lifetime value research in marketing: A review and future directions', Journal of Interactive Marketing, Vol. 16, No. 2, pp. 34-46.

12 Box, G. E. P. and Draper, N. R. (1987) 'Empirical Model-Building and Response
Surfaces', John Wiley \& Sons, New York, NY.

13 Hansotia, B. (1990) 'Sample size and design of experiment issues', Journal of Direct Marketing, Vol. 4, No. 4, pp. 15-25.

14 Hansotia, B. (1992) 'Analytic methods', in Nash, E. L. (ed.) 'The Direct Marketing Handbook', 2nd edn, McGraw-Hill, New York, NY, pp. 570-587.

15 Hansotia, B. (1992) 'Determination of panel sizes in designed experiments', Journal of Direct Marketing, Vol. 6, No. 4, pp. 17-27.

16 Hansotia, B. (1995) 'Attrition analysis for continuities in the US', Journal of Targeting, Measurement and Analysis for Marketing, Vol. 3, No. 3 , pp. $268-280$.

17 Hansotia, B. and Rukstales, B. (2002) 'Incremental value modeling', Journal of Interactive Marketing, Vol. 16, No. 3, pp. 35-46.

18 Bell, D. et al. (2002) op cit.

19 DeSarbo, W. S., Wedel, M., Vriens, M. and Ramaswamy, V. (1992) 'Latent class metric conjoint analysis', Marketing Letters, Vol. 3, No. 3, pp. 273-288.

20 DeSarbo, W. S., Huff, S., Rolandelli, M. and Choi, J. (1993) 'On the measurement of perceived service quality: A conjoint analysis approach', in Rust, R. and Oliver, R. (eds), 'Handbook of Service Quality', Sage Press, Thousand Oaks, CA. 